\title{
Discussion on Main Protection Configuration Schemes for Stator Internal Short Circuits in SF600-42/1308 Generator
}

\author{
Lv Yan Ling, Tengchong, Ge Bao Jun, Wen Ruxin, Xiao Shiyong, Li Mengqiao \\ Harbin University of Science and Technology, Harbin, 150080, china \\ Yanling0828@163.com
}

\begin{abstract}
Choosing a correct main protection configuration schemes for stator internal short circuits in generator is the premise of safe and reliable operation of the large generator. This paper firstly analyzes the general large hydro-generator stator internal short circuit fault type and fault number. It mainly does some statistics works on SF600-42/1380 generator fault location and fault number. And then through the finite element method, calculate each phase and each branch current if the generator internal short circuit happens. In the paper, we calculate the sensitivity of various kinds of main protection scheme. Get the dead zone position which easily lets the main protection device take action. Finally we summarize various factors that determine SF600-42/1380 generator main protection scheme of configuration.
\end{abstract}

Keywords: large generators; internal faults; sensitivity; main protection configuration

\section{Introduction}

Internal short circuit in large generator generates a large short-circuit current, the short circuit current will not only seriously threaten the safety of generator's operation but also can cause huge economic losses. In order to ensure the quality of electrical power and the stability of power transmission, it is necessary to equip the generator with highperformance internal short circuit main protection scheme.

For main protection configuration problem, many scholars have conducted research work in many aspects. Reference [1] proposed a method to simplify the process of design of main protection configuration scheme for large-sized hydro-generators with odd branches. To avoid the huge workload of "enumeration method", reference [2]proposed two principles of selecting branch. Reference[3-4] has respectively analyzed and compared the main protection configuration scheme of ertan power station, longtan power station, muruo power station, sanxia power station, and at the same time, expatiated the quantitative design process of generator main protection configuration; Engineering always use the equal or close capacity of generator as a justification for they copy each other's main protection configuration scheme. Reference[5] corrected this mistake and put forward a process of optimization design; Reference[8]has done an in-depth study on the method of analysis generator stator inter-turn short circuit and all kinds of inter-turn protection and filtering algorithm. Reference[6-7] introduced the large generator internal fault current calculation method, and analyzed the main protection configuration according to the short-circuit current. All kinds of references above use large generator as an example to introduce the quantitative design process of generator main protection configuration.

This paper mainly analyzes the general large hydro-generator stator winding internal short circuit fault type and fault number, emphasizes some statistics on generator fault position and fault number, and then through the finite element method calculates generator stator in each phase and each branch current in case the generator internal short 
circuit occurs, calculating the sensitivity of main protection scheme, get the dead zone position which easily let the main protection to take act. Finally the paper summarizes various factors determining SF600-42/1380 generator main protection scheme of configuration, as a reference for subsequent large-scale hydropower generator designation and selection of main protection scheme.

\section{The Fault Type and Fault Number Statistics}

Before designing main protection configuration scheme, analysis of the fault types and fault number is particularly important, which are the basis and prerequisite for all subsequent works. The main consideration of generator stator winding fault is the slot and end winding bar because of insulation damage or other reasons caused by the fault. Insulation damage between upper and lower winding bar in the same slot caused short circuits, which is stator slot short-circuit faults. Insulation damage in winding endcross caused short circuits, which is stator end short-circuit faults.

After distinguishing the fault types, we need to confirm the fault number in each stator winding configuration according to stator winding coil configuration. So we analyzed configuration mode of double-layer wave winding and lap coil winding. In double-layer wave winding and lap coil winding configuration mode we obtained the statistics number of stator slot short-circuit faults and stator end short-circuit faults that might happen.

\subsection{Stator Slot Short-circuit Faults}

Not only for double-layer wave winding but also for lap coil winding, as long as it is short circuit in slot, the total number of fault is equal to the total number of stator slot $\mathrm{Z}$. That is to say the total number of slot short circuit faults in phase in the same branch, slot short circuit faults in phase in different branch, slot circuit faults inter phrase in same branch, slot circuit faults inter phrase in different branch is $\mathrm{Z}$.

\subsection{Stator End Short-circuit Faults}

There are many cross in winding end. When the insulation of the cross are destroyed, the end cross short-circuit fault will happen.

Firstly we analyze the fault number of wave winding. As figure 2-4 shows, we take a winding bar in upper winding slot as example. It was divided into inner slot part and end part, the end part was divided into upper part and lower part. Look at the upper part, the upper part cross $\mathrm{y}_{1}$ number of slot, there would be $\left(\mathrm{y}_{1}-1\right)$ number of upper part of lower winding cross with it. The cross will produce $\left(\mathrm{y}_{1}-1\right)$ number of end short-circuit faults. The lower part cross $y_{2}$ number of slot, there would be $\left(y_{2}-1\right)$ number of lower part of lower winding cross with it. The cross will produce $\left(y_{2}-1\right)$ number of end short-circuit faults. In conclusion, there are $\left(\mathrm{y}_{1}+\mathrm{y}_{2}-2\right)$ number of end short-circuit faults in a winding bar, so the whole stator wave winding would have $\mathrm{Z}\left(\mathrm{y}_{1}+\mathrm{y}_{2}-2\right)$ number of stator end shortcircuit faults.

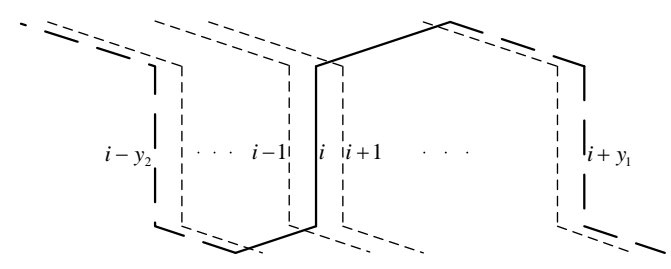

Figure 1. The Fault that may Happen in Wave Winding End

Then analyze the number of lap coil winding fault. As figure 2-5 shows, we take a 
winding bar in upper winding slot as example. It was divided into upper part and lower part. Look at the upper part, the upper part cross $\mathrm{y}_{1}$ number of slot, there would be $\left(\mathrm{y}_{1}-1\right)$ number of upper part of lower winding cross with it. The cross will produce $\left(\mathrm{y}_{1}-1\right)$ number of end short-circuit faults. The lower part cross $y_{2}$ number of slot, there would be $\left(y_{2}-1\right)$ number of lower part of lower winding cross with it. The cross will produce $\left(y_{2}-1\right)$ number of end short-circuit faults. In conclusion, there are $\left(\mathrm{y}_{1}+\mathrm{y}_{2}-2\right)$ number of end shortcircuit faults in a winding bar, so the whole stator lap coil winding would have $\mathrm{Z}\left(\mathrm{y}_{1}+\mathrm{y}_{2}-2\right)$ number of stator end short-circuit faults.

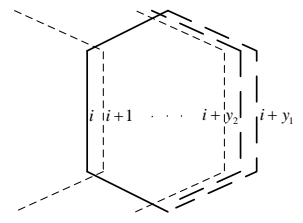

\section{Figure 2. The Fault that May Happen in Lap Coil Winding End}

So as we can see, both in wave winding and lap coil winding the number of stator slot short-circuit faults is $Z$, the number of stator end short-circuit faults is $Z\left(y_{1}+y_{2}-1\right)$. The total number of short-circuit faults is the sum of both stator end short-circuit faults and stator end short-circuit faults: $\mathrm{Z}\left(\mathrm{y}_{1}+\mathrm{y}_{2}-1\right)$. Next, we analyze fault type and fault number of SF600-42/1308 wave winding generator.

For SF600 - 42/1308 generator, it has 42 poles, wave winding, slot number are integer. Its stator has 504 slots, and each phase has 6 branches, stator winding pitch are $\mathrm{y}_{1}=14$ $\mathrm{y}_{2}=10$, whose fault statistics was shown in table 1 .

Table 1. SF600-42/1308 Stator Internal Short Circuits Fault Type and Fault Number Statistics

\begin{tabular}{c|c|c}
\hline & $\begin{array}{c}\text { Stator slot short- } \\
\text { circuit faults }\end{array}$ & $\begin{array}{c}\text { Stator end short- } \\
\text { circuit faults }\end{array}$ \\
\hline $\begin{array}{c}\text { slot short circuit faults in phase } \\
\text { in the same branch }\end{array}$ & 234 & 252 \\
\hline $\begin{array}{c}\text { slot short circuit faults in phase } \\
\text { in different branch }\end{array}$ & 18 & 3024 \\
\hline $\begin{array}{c}\text { slot circuit faults inter phrase } \\
\text { in the same branch }\end{array}$ & 0 & 1572 \\
\hline $\begin{array}{c}\text { slot circuit faults inter phrase } \\
\text { in different branch }\end{array}$ & 252 & 6240 \\
\hline total & 504 & 11088 \\
\hline
\end{tabular}

\section{The Calculation of Sensitivity}

"Guide of Calculating Settings of Relay Protection for Large Generator and Transformer" stipulates the way of designing the main generator internal short-circuit protection. Generator calibration coefficient sensitivity $K_{\text {sen }}$ is used as standard. When $K_{\text {sen }} \geq 1.5$, the main protection can take action sensitively. Sensitivity coefficient calculation formula:

$$
K_{\text {sen }}=I_{d}{ }^{*} / I_{o p}{ }^{*}
$$

$I_{d}{ }^{*}$ is differential current of all kinds of main protection. $I_{o p}{ }^{*}$ is the corresponding 
actuating current, which depends on the choice of protection criterion type. The specific calculation method can be referred to reference [8].

\section{Four Kinds of Main Protection and its Performance Analysis}

\subsection{Zero-sequence Current Transverse Differential Protection}

Zero-sequence current transverse differential protection, also known as the unit transverse differential protection, divides stator winding into two parts or three parts, and detects the zero sequence current between the parts[8]. Zero-sequence current transverse differential protection is a kind of overcurrent protection, when the current exceeds a predetermined maximum protection. It is suitable for stator winding with many branches, which is widely used in large generators, to the generator stator winding interturn short circuit it has a higher sensitivity.

\subsection{Split Phase Transverse Differential Protection}

Because designing main protection of generator internal short-circuit at least has a transverse and longitudinal, but zero-sequence current transverse differential protection does not apply to the generator which only has one neutral point outside generator. Split phase transverse differential protection divides each phase parallel branches in the generator neutral point side into 2 groups (Completely split phase transverse differential protection), or after giving up one branch then divide remaining winding into two groups (incomplete split phase protection). Main reaction generator internal fault of interturn short circuit, compares the current unbalance between two parts in phase.

\subsection{Incomplete Longitudinal Differential Protection}

Incomplete longitudinal differential protection is the more commonly used one of "two longitudinal". It connects the current transformer to neutral point side of each phase in partial parallel branch windings, with the machine side current transformer constitute the incomplete differential protection. Incomplete differential protection can not only reflect the interphase short circuit, but also can reflect the interturn short circuit.

\subsection{Complete Longitudinal Differential Protection}

Completely longitudinal differential protection is a kind of traditional differential protection, which compares whether the head end current of the generator stator winding and the end current of the generator stator winding are balanced. Interphase short circuit for the stator winding is very sensitive, and can only respond with interphase short circuit fault. Complete longitudinal differential protection consists of neutral side current transformer which connects from all parallel branches winding in a phase and generator side current transformer.

\section{Main Protection Configuration Schemes for Stator Internal Short Circuits in SF600-42/1308 Generator}

\subsection{Ways of Stator Winding Branch Outlet}

For SF600-42/1380 large generators, the stator winding branch number is 6 . There are many combinations of branch outlet, which can be divided into two neutral points and three neutral points. When there are two neutral points, each group is introduced 3 branches current separately. There are 10 kinds of possible grouping situation 123-456、 $124-356 、 125-346,126-345 、 134-256 、 135-246 、 136-245 、 145-236 、 146-235$ 、 
156-234; When there are three neutral points, each group is introduced 2 branches current separately. Take the adjacent branch combination 12-34-56 and branches apart combinations 13-25-46 into consideration.

\subsection{The Composition of Main Protection}

The main protection of large generator is generally configured in the form of the combination of main protection, at least "a transverse and longitudinal" two main protection. Transverse differential protection is prior to zero sequence current type transverse differential protection, before considering other primary protection. In order to improve the performance of main protection configuration scheme, generally on the premise of no additional current transformer TA, split phase transverse differential protection is added in the zero sequence current type of transverse differential protection.

Choose main protection configuration when there are two neutral points. The main protection can be constituted are as follows:

Zero-sequence current transverse differential protection:TA0;

Complete Split phase transverse differential protection: TA1-TA2;

complete longitudinal differential protection: (TA1+TA2)-TA7;

Incomplete longitudinal differential protection: TA1-TA7; TA2-TA7。

(As shown in figure 3and 4 Take A phase as an example)

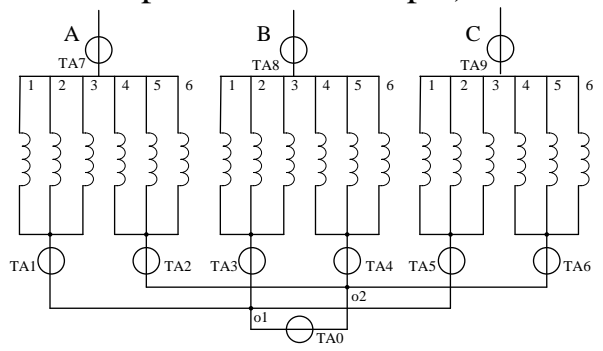

Figure 3. Two Neutral Points Main Protection Configuration

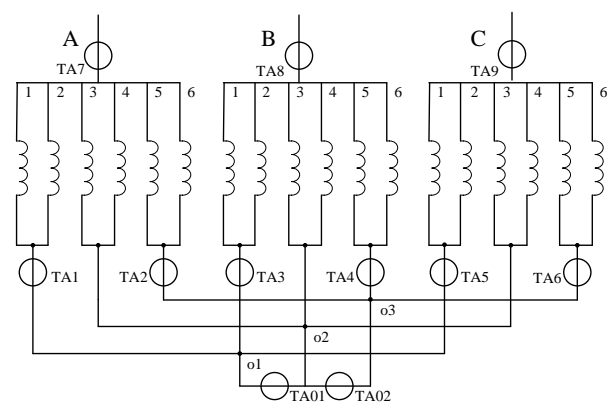

Figure 4. Three Neutral Points Main Protection Configuration

\subsection{Ways of Configuring Main Protection Combination Scheme}

Use finite element method to calculate when SF600-42/1380 generator idle load gridconnection, Internal short circuit of the stator winding of each phase and each branch of periodic component of short-circuit current occurs. According to "Research of main protection configuration scheme for internal short circuit of large generators", the sensitivity of the main protection scheme for the main protection scheme of performance is calculated, the action performance of each main protection scheme is gotten, and the following short circuit which reduce the sensitivity of main protection scheme is obtained, one or several of the main protection dead zone is formed :(1) The small number of turns with the same branch in phase short circuit, makes each phase neutral side branch current have little change compared with the current before failure happens, thus reduce the 
sensitivity of main protection scheme, and form the action dead zone;(2) To the different branch for similar potential in phase turn-to-turn short circuit, non-fault branch current of fault phase is small, two fault branch current of fault phase cancel each other, so the current through the current transformer is also small. (3) For interphase short circuit, short circuit coil number is less and near the neutral point side, so two short-circuit point of electric potential difference is small, before and after the little fault current change, making the main protection current action small, therefore, it is easy to form a dead zone $^{[9]}$. As shown in figure 5 , when there are two neutral points, the relationship between every kinds of main protection sensitivity and the number of two short circuit windings is different. Figure (a) is the comparison analysis of Zero-sequence current transverse differential protection sensitivity when there are two neutral points; figure (b) is comparison analysis of the sensitivity of two split phase transverse differential protection for interturn short circuit faults in phase in the same branch. Figure (c) is comparison analysis of the sensitivity of two split phase transverse differential protection for interturn short circuit faults in phase in different branches. Figure (d) is the comparison analysis of incomplete longitudinal differential protection sensitivity when introducing different number of branches.

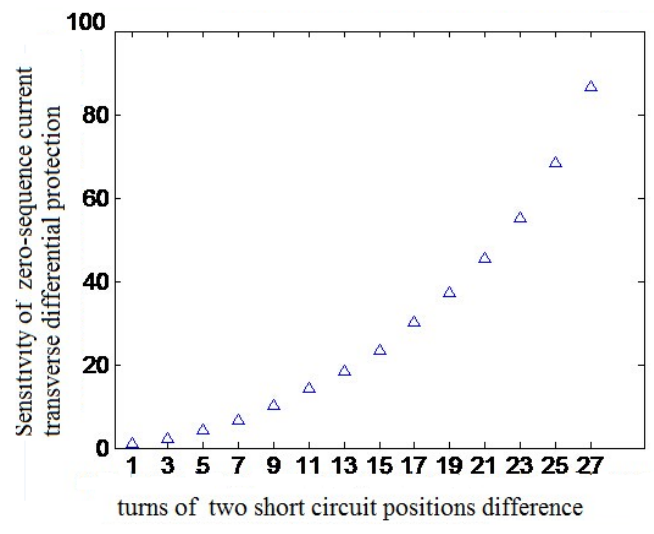

(a)

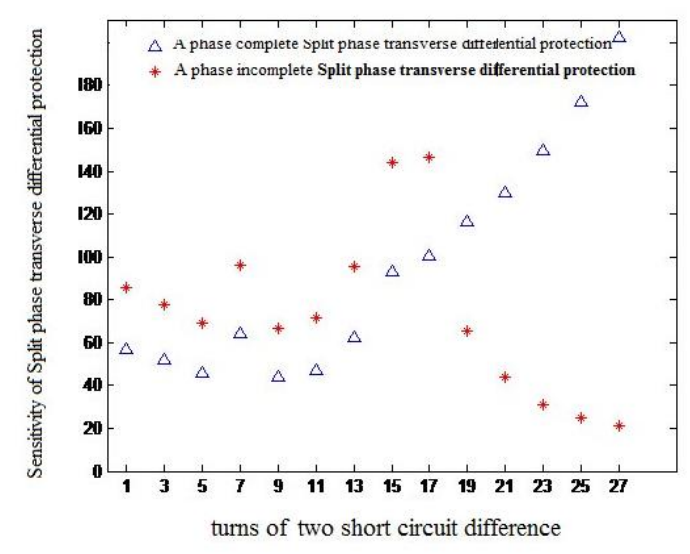

(c)

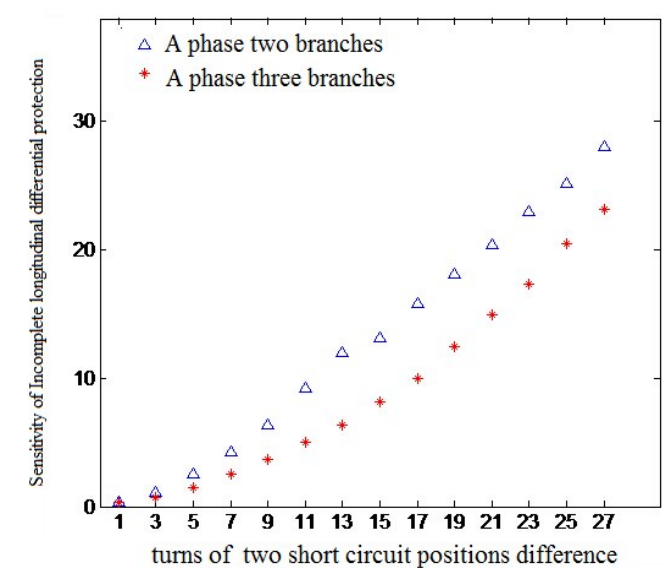

(b)

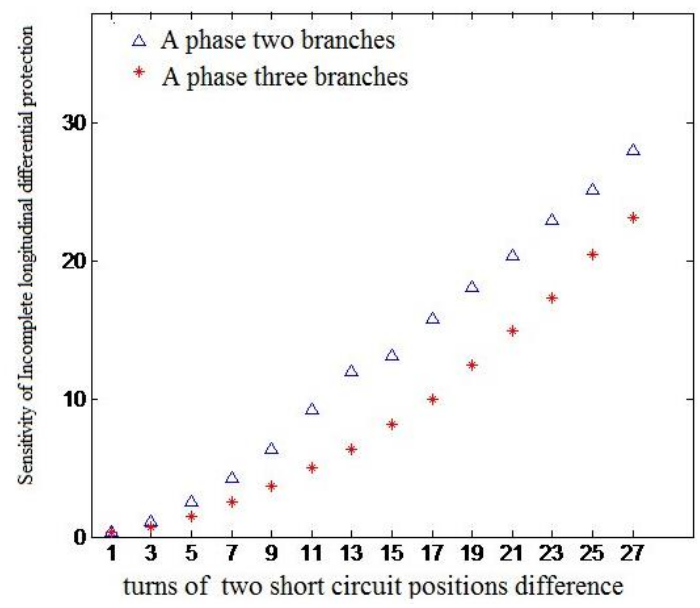

(d)

Figure 5. Two Neutral Points, the Two Short-circuit Point Location Different Number of Turns and the Relations of Various Kinds of Main Protection Sensitivity 


\section{Table 2. Statistic of Generator in a Slot Fault Number and Number of Turns which is Easy to Form Dead Zone}

\begin{tabular}{|c|c|c|c|c|c|c|c|c|c|c|c|c|c|c|c|}
\hline \multirow{4}{*}{$\begin{array}{l}\text { Fault type } \\
\\
\text { Number of } \\
\text { short } \\
\text { circuit } \\
\text { turns(turn) }\end{array}$} & \multirow{2}{*}{\multicolumn{8}{|c|}{$\begin{array}{l}\text { In phase short circuit in same branch } \\
\qquad(234)\end{array}$}} & \multirow{2}{*}{\multicolumn{2}{|c|}{$\begin{array}{c}\text { In phase } \\
\text { short circuit } \\
\text { in different } \\
\text { branches } \\
\text { (18) }\end{array}$}} & \multicolumn{5}{|c|}{$\begin{array}{c}\text { interphase short circuit }(252 \\
\text { turns })\end{array}$} \\
\hline & & & & & & & & & & & \multirow{2}{*}{$\begin{array}{l}\text { Branch } \\
\text { number } \\
\text { of the } \\
\text { same } \\
(0)\end{array}$} & \multicolumn{4}{|c|}{$\begin{array}{l}\text { Branch number of } \\
\text { different }(252)\end{array}$} \\
\hline & & & & & & & & More & & \multirow[b]{2}{*}{21} & & & & & \\
\hline & 1 & 2 & 3 & 4 & 5 & 6 & 7 & $\begin{array}{l}\text { than } \\
8\end{array}$ & 7 & & 0 & 2 & 3 & 4 & 5 \\
\hline $\begin{array}{c}\text { Number of } \\
\text { fault }\end{array}$ & 9 & 9 & 9 & 9 & 9 & 9 & 9 & 171 & 9 & 9 & 0 & 90 & 72 & 54 & 36 \\
\hline $\begin{array}{l}\text { Number of } \\
\text { dead zone } \\
\text { which is } \\
\text { easy to } \\
\text { form } \\
\text { protection }\end{array}$ & 9 & 9 & 9 & 9 & 0 & 0 & 0 & 0 & 0 & 0 & 0 & 36 & 0 & 0 & 9 \\
\hline
\end{tabular}

Table 3. Statistic of Number of Generator End Terminal Fault and Number of Turns in which is Easy to Form Dead Zone

\begin{tabular}{|l|l|l|l|l|l|l|l|l|l|l|l|l|l|l|}
\hline Fault type & \multicolumn{7}{|c|}{ In phase short circuit in same branch(252) } \\
\hline $\begin{array}{c}\text { Number of } \\
\text { (3024) } \\
\text { short circuit } \\
\text { turns(turn) }\end{array}$ & 1 & 2 & 3 & 4 & 5 & 6 & 7 & $\begin{array}{c}\text { More } \\
\text { than } 8\end{array}$ & 0 & 1 & 2 & 3 & 4 & $\begin{array}{c}\text { More than } \\
5\end{array}$ \\
\hline $\begin{array}{c}\text { Number of } \\
\text { fault }\end{array}$ & 9 & 9 & 9 & 9 & 9 & 9 & 9 & 171 & 126 & 54 & 126 & 18 & 18 & 2847 \\
\hline $\begin{array}{c}\text { Number of } \\
\text { dead zone } \\
\text { which is easy } \\
\text { to form } \\
\text { protection }\end{array}$ & 9 & 9 & 9 & 9 & 0 & 0 & 0 & 0 & 126 & 54 & 126 & 18 & 18 & 0 \\
\hline
\end{tabular}

Continue table 3
\begin{tabular}{|c|c|c|c|c|c|c|c|c|c|c|}
\hline \multicolumn{10}{|c|}{ interphase short circuit (7812) } & \multicolumn{7}{c|}{$\begin{array}{c}\text { Branch number of different } \\
\text { Branch number of the same } \\
\text { (1572) }\end{array}$} \\
\hline 2 & 3 & 4 & 5 & $\begin{array}{c}\text { More } \\
\text { than 5 }\end{array}$ & 1 & 2 & 3 & 4 & 5 & $\begin{array}{c}\text { More } \\
\text { than } \\
5\end{array}$ \\
\hline 288 & 288 & 126 & 114 & 756 & 243 & 294 & 495 & 603 & 420 & 4185 \\
\hline 48 & 36 & 12 & 6 & 0 & 45 & 24 & 72 & 132 & 12 & 0 \\
\hline
\end{tabular}

Then a variety of main protection scheme combinations in the position where it is easy to form the dead zone of the short circuit is analyzed, and the best main protection scheme is found. To determine the final main protection configuration scheme, it is necessary to consider the following indicators: (1) neutral side branch which is easy to outlet; (2) it is simple to complete the internal short circuit protection function used in the 
protection scheme; (3) the number of the current transformer is few. (4)The fault whose main protection cannot take action is less; (5) the fault whose main protection can take double action is much. (6) Internal short circuit protection dead zone accounted for small proportion of the total number of failure. After considering all the above situation, we recommend the final main protection configuration scheme is a set of zero-sequence current transverse differential protection, a set of complete split phase transverse differential protection and two sets of incomplete longitudinal differential protection. Branch combination is $\left\{\begin{array}{lll}1 & 3 & 5\end{array}\right\}$ and $\{2,4,6\}$.

\section{Conclusions}

This article through the analysis of SF600-42/1380 main protection configuration scheme, can draw the following conclusion:

(1) Before determining the generator main protection configuration scheme, we must analyze the position and the type of generator fault that might happen.

(2) The way of outlet of the stator winding branch is closely related with the protective effect of various main protection, through the analysis of different neutral point, clear stator winding branch outlet type and stator winding branch outlet number and different branch combination way have what influence on interturn short circuit protection.

(3) Determination of the generator main protection configuration scheme, is not only related to the sensitivity of various main protection, but also need to consider the various factors.

\section{Acknowledgements}

Research Fund for the Doctoral Program of Higher Education of China(20132303120001) Project Supported by National Natural Science Foundation of China (51407049).

\section{References}

[1] L. Gui, W. J. Wang, Y. G. Sun and X. H. Wang, "Design Characteristic of Main Protection Configuration Scheme for Large-sized Hydro-Generators with Odd Branches", Proceedings of the CSEE, vol. 26, no. 22, (2006), pp. 29-34

[2] Y. G. Sun, X. H. Wang and L. Gui, "Optimization Design of Main Protection Configuration Scheme for Iinternal Faults of Generator With Even Multi-Branches”, Automation of Electric Power Systems, vol. 29, no. 12, (2005), pp. 83-92.

[3] W. J. Wang, X. H. Wang and L. Gui, "Research on the Main Protection Configuration Scheme for Internal Faults of Longtan Generator", Automation of Electric Power Systems, vol. 29, no. 1, (2005), pp. 83-88.

[4] Q. Zhou, Y. Q. Gui and Q. T. Zeng, "Research on main protection of hydro-generators and protection design of Murum Hydropower Station”, Yangtze River, vol. 8, no. 44, (2013), pp. 79-93.

[5] L. Gui, X. H. Wang, Y. G. Sun and W. J. Wang, "Optimum Design of Main Protection Configuration Scheme for Large Generators", Journal of Tsinghua University (Science and Technology), vol. 45, no. 1, (2005), pp. 141-144.

[6] J. J. Huang, "Research on the Inter-turn Fault Protection for Stator Windings of Generators", Hangzhou, zhejiang university, (2008).

[7] "Research on Optimum Design of Main Protection Configuration Scheme for Large Generators", Beijing Tsinghua University, (2003).

[8] S. H. Lou, D. S. Chen and X. Y. Yin, "Computation \& Analysis of the Sensitivity of Main Protective Relay for the Internal Fault of Large Hydro-Generator", Automation of Electric Power Systems, vol. 25, no. 7, (2001), pp. 36-39.

[9] R. X. Wen, "Research of main protection configuration scheme for internal short circuit of large generators", Harbin university of science and technology, (2014). 